\title{
Aspirin related gastrointestinal bleeders have an exaggerated bleeding time response due to aspirin
} use

\author{
A I Lanas, M T Arroyo, F Esteva, R Cornudella, B I Hirschowitz, R Sáinz
}

\begin{abstract}
Background-Gastrointestinal bleeding is related to non-steroidal anti-inflammatory drug (NSAID) use, especially aspirin, but only a small subset of users bleed.

Aim-To look for risk factors or mechanisms whereby aspirin may promote gastrointestinal bleeding.

Patients-Sixty one patients with previous aspirin related upper gastrointestinal bleeding and 61 matched controls.

Methods-Patients and controls were given $375 \mathrm{mg}$ of aspirin and sequential skin bleeding time and blood aspirin levels were measured. Additional studies included platelet lumiaggregation, von Willebrand factor, Factor VIII, and coagulation studies.

Results-Baseline skin bleeding time was similar in bleeders and controls, but bleeders had a more prolonged skin bleeding time after aspirin use. Hyperresponse was more frequent in bleeders $(30 \% v 9.3 \% ; \mathbf{p}<0.01)$ and was associated with more than one previous separate bleeding event and a lower packed cell volume during the preceding bleeding episode. No differences were found in other factors studied. Logistic regression analysis identified prolonged skin bleeding time after aspirin use as an independent factor contributing to aspirin related gastrointestinal bleeding $(R R=5 \cdot 4$; 95\% CI: 1.8 to $17 \cdot 1)$.
\end{abstract}

Conclusions-30\% of patients with a history of aspirin related gastrointestinal bleeding have an exaggerated prolongation of skin bleeding time in response to aspirin, which may be a risk factor for bleeding. This intrinsic defect is not related to any known platelet defect or to subclinical von Willebrand disease or different aspirin metabolism.

(Gut 1996; 39: 654-660)

Keywords: gastrointestinal bleeding, aspirin, skin bleeding time, platelet, NSAIDs, von Willebrand factor.

Division of

Gastroenterology University of Alabama at Birmingham, USA B I Hirschowitz

Correspondence to: Dr A Lanas,

Servicio de Aparato

Digestivo, Hospital Clinico Universitario, 50009 Zaragoza, Spain.

Accepted for publication 20 June 1996
Through the combined use of history objective testing by platelet cyclooxygenas activity, gastrointestinal bleeding is associated with non-steroidal anti-inflammatory drug (NSAID) use in over $80 \%$ of cases and $87 \%$ of that use is aspirin, alone or combined with other NSAIDs. ${ }^{1}$ However, it is apparent that most of those using aspirin/NSAIDs are free of complications. The calculated risk of major bleeding is small, and it has been estimated to be between only 1 in 10000 and 1 in 20000 NSAID prescriptions. ${ }^{2}{ }^{3}$ However, because so many such prescriptions are issued, the actual risk translates into high figures in absolute and clinical practice terms. Bleeding thus often seems to be a direct consequence of NSAIDs and especially aspirin use. However, the mechanisms whereby aspirin or other NSAIDs might promote or induce bleeding in only a small proportion of users are not known. Several potential mechanisms for NSAID complications have been proposed ${ }^{4}$ and include: a failure of the gastroduodenal mucosa to adapt to NSAID damage; a change in the mucosal balance between injurious/protective factors in susceptible people leading to increased severity of the ulcer diathesis and complications; inhibition of platelet and platelet dependent clotting mechanisms, precipitating gastrointestinal bleeding, particularly in the presence of gastrointestinal lesions. In this way, it has been shown that, when tested within six hours of hospital admission, most aspirin related acute gastrointestinal bleeders had an abnormal increase in skin bleeding time, which reversed to normal within several days. ${ }^{5}$ It is also well known, however, that aspirin inhibits platelets in everyone $e^{67}$ and bleeding may follow small and even single doses of aspirin.

Therefore, to look for potential risk factors or a possible mechanism whereby aspirin may promote gastrointestinal bleeding, this study was undertaken to examine whether patients with a history of aspirin related gastrointestinal bleeding might have a different bleeding response to aspirin use or to suffer from any potential subclinical platelet dependent or independent pathological condition (for example, von Willebrand disease) that could promote bleeding when using aspirin.

\section{Methods}

PATIENTS AND CONTROLS

To maximally homogenise the sample, only patients with a previous and recent history of gastrointestinal bleeding associated with aspirin use within five days of hospital admission were eligible for inclusion in the study. The study was performed on 61 patients, at least two months after the bleeding episode, and once the lesions were endo- 
scopically healed. Sixty one age and sex matched controls with no history of gastrointestinal bleeding were selected at random from among those people attending general practitioners. Patients younger than 18 or older than 80 were excluded as well as those with concomitant severe disease. Other exclusion criteria included patients with hypertension, diabetes, cirrhosis, uraemia, previous gastric surgery, malabsorption, drug addiction including alcohol, pregnancy, lactation, or those who had known primary haematological disorders, and those using and unable to stop taking NSAID or anticoagulants. No antisecretory drugs, or any other drugs were permitted within five days of the start of the study and all patients gave informed consent.

The study protocol was approved by the Institutional Review Board of the University Hospital of Zaragoza, and all patients and controls gave informed consent to the study, which was conducted in accordance with the declaration of Helsinki concerning studies in human subjects.

\section{Study protocol}

A detailed clinical history was made for each subject of the study. All bleeders had previously been inpatients in the University Hospital. Before the studies, current aspirin use was ruled out by measuring either platelet cyclooxygenase activity or platelet lumiaggregation studies, or both. The study protocol included: (a) sequential skin bleeding times before and after aspirin use, (b) the measurement of aspirin and salicylic acid plasma concentrations, (c) platelet lumiaggregation and standard blood counts and coagulation studies, (d) determination of von Willebrand factor in vitro, ristocetin cofactor assay, and Factor VIII.

\section{Skin bleeding time test}

After an overnight fast, all patients and controls were given $375 \mathrm{mg}$ of aspirin (Adiro; Bayer, Spain) at 9 am and sequential skin bleeding times were measured at $0,2,4,6$, and 24 hours after aspirin use. Skin bleeding time was always measured by the same person unaware of the goals of the study, using a disposable 'Surgicut' (International Technidyne Corp, Edison, NJ). This device makes a fully automated and standardised incision of $5 \mathrm{~mm}$ in length and 1 $\mathrm{mm}$ in depth with a number 1 surgical blade housed in the self contained unit. These particular dimensions give sensitive and reproducible test results. ${ }^{8}$ The incision was made on the volar surface of the forearm $5 \mathrm{~cm}$ below and parallel to the antecubital crease, avoiding surface veins, scars, bruises, and oedematous areas. A blood pressure cuff on the upper arm was inflated $40 \mathrm{~mm} \mathrm{Hg}$ throughout the test. Without touching the wound, filter paper was used to remove blood every 30 seconds until a clot was formed. Skin bleeding time was recorded to the nearest 30 seconds. ${ }^{9}{ }^{10}$ For this size wound the mean skin bleeding time performed in our centre in preliminary studies in 100 people was $2 \cdot 78$ and the upper limit was six minutes with skin bleeding time -5.5 minutes in 96 of 100 . Similar results were obtained in another study using this device. ${ }^{5}$

\section{Aspirin and salicylic acid blood concentrations}

Aspirin and salicylic acid blood values were measured by high performance liquid chromatography on a $4 \mu \mathrm{m}$ ultrasphere C18 silica column $(150 \times 3.9 \mathrm{~mm}$, Waters, Millipore Iberica, Madrid, Spain) according to a method previously described. ${ }^{11}$ Blood samples before and after aspirin use were placed in an ice water bath, treated with $10 \mu \mathrm{l} / \mathrm{ml}$ of $50 \%(\mathrm{v} / \mathrm{v})$ potassium fluoride (an enzyme inhibitor) to avoid aspirin hydrolysis, and centrifuged for three minutes. The supernatant was then acidified and extracted with diethyl ether (1:3; $\mathrm{v} / \mathrm{v})$ for 20 minutes, which permits recoveries over $80 \%$. The organic phase of the extract was then evaporated under nitrogen and stored at $-20^{\circ} \mathrm{C}$. Samples were reconstituted in $500 \mu \mathrm{l}$ of mobile phase (acetonitrile/water/TFA; $30 / 70 / 0 \cdot 01$; v:v) and $20 \mu \mathrm{l}$ aliquots of the reconstituted sample were applied to a reverse phase high performance liquid chromatography (Waters 600E, Millipore). Aspirin and its metabolite absorbances were measured at $237 \mathrm{~nm}$. Toluic acid (Sigma, St Louis, MO) was used as the internal standard $(20 \mu \mathrm{g} / \mathrm{ml})$. The method shows a high correlation between doses and areas (aspirin, $r=0.9383$; salicylic acid, $r=0.9896$ ) and the sensitivity was 0.20 $\mu \mathrm{g} / \mathrm{ml}$ for aspirin and $0.40 \mu \mathrm{g} / \mathrm{ml}$ for salicylic acid. Aspirin and salicylic acid concentrations over time were determined by comparison of standards (Sigma, St Louis, MO) and unknown chromatographic peak areas with an integrator (Waters 746, Millipore) connected to the main station.

\section{Platelet studies}

Platelet studies were performed from blood obtained in citrated tubes at time 0 , before the patient was given aspirin. Platelet cyclooxygenase activity was measured by the production of thromboxane $\mathrm{B}_{2}$ from ${ }^{14} \mathrm{C}$ arachidonic acid (New England Nuclear, Itisa, Madrid, Spain) according to a method previously described and validated elsewhere. ${ }^{12}$ This method has been shown to be very sensitive for detecting aspirin use within five days of testing.

Platelet lumiaggregation studies were assessed with a lumiaggregometer (Aggrecorder II PA 322, Menarini, Barcelona, Spain). Aggregation in response to the agonists thrombin, collagen, arachidonic acid, adrenaline, ADP, and ristocetin were determined in platelet rich plasma. Defects in thromboxane production, such as those caused by NSAIDs, impair aggregation and ATP release induced by arachidonic acid, but not by thrombin or ristocetin. Isolated abnormalities of response to ristocetin can identify patients with common variety and variant von Willebrand's disease or defects of platelet glycoprotein IbIX. Storage pool deficiency is one cause of prolonged skin 
TABLE I Clinical and analytical data from patients and controls

\begin{tabular}{|c|c|c|c|}
\hline & $\begin{array}{l}\text { Bleeders } \\
(n=61) \\
\text { (Excluded 3) }\end{array}$ & $\begin{array}{l}\text { Controls } \\
(n=61) \\
\text { (Excluded 5) }\end{array}$ & Significance \\
\hline $\begin{array}{l}\text { Sex (\% males) } \\
\text { Age range (mean (SD)) }\end{array}$ & $\begin{array}{l}74 \\
26-79(57 \cdot 5(14))\end{array}$ & $\begin{array}{l}62 \\
23-78(53 \cdot 5(15 \cdot 4))\end{array}$ & $\begin{array}{l}\text { NS } \\
\text { NS }\end{array}$ \\
\hline \multicolumn{4}{|l|}{ Source of bleeding: } \\
\hline $\begin{array}{l}\text { upper GI* } \\
\text { lower GI† }\end{array}$ & $\begin{array}{r}53 \\
5\end{array}$ & - & \\
\hline $\begin{array}{l}\text { Forrest classification } \\
\text { ( } 45 \text { peptic ulcers) }\end{array}$ & $\begin{array}{l}\mathrm{Ib}=2 \\
\mathrm{II}=8 \\
\mathrm{III}=35\end{array}$ & & \\
\hline $\begin{array}{l}\text { Type of aspirin use: } \\
\text { long term } \\
\text { sporadic }\end{array}$ & $\begin{array}{l}30(51 \cdot 7 \%) \\
28(48 \cdot 2 \%)\end{array}$ & & \\
\hline $\begin{array}{l}\text { Reasons for aspirin use: } \\
\text { cardiovascular disease }(\%) \\
\text { rheumatic disorders }(\%) \\
\text { OTC } \neq(\%)\end{array}$ & $\begin{array}{l}17(29 \cdot 3) \\
13(22 \cdot 4) \\
28(48 \cdot 2)\end{array}$ & & \\
\hline Alcohol (\%) & $27 \cdot 5$ & 16 & NS \\
\hline \multirow{2}{*}{\multicolumn{4}{|c|}{ Analytic }} \\
\hline & & & \\
\hline Packed cell volume (\%) & $42 \cdot 5(3 \cdot 8)$ & $41 \cdot 2(4 \cdot 3)$ & NS \\
\hline BUN (mg/dl) & $18.9(5 \cdot 3)$ & $16 \cdot 6(6 \cdot 2)$ & NS \\
\hline Bilirubin (mg/dl) & $0.4(0.2)$ & $0.5(0.2)$ & NS \\
\hline Platelets $\left(/ \mathrm{mm}^{3}\right)$ & $233(45 \cdot 4)$ & $230 \cdot 8(50 \cdot 5)$ & NS \\
\hline
\end{tabular}

NS=not significant. $\star$ Peptic ulcer $=45$ ( 25 duodenal ulcers; four pyloric ulcers, 16 gastric ulcers), acute mucosal lesions $=8$. $†$ Diverticulosis $=5$. $¥ O T C=$ non-prescription over the counter.

$\mathrm{GI}=$ gastrointestinal tract. $\mathrm{BUN}=$ blood urea nitrogen.

bleeding time $\mathrm{e}^{13}$ and is shown by reduction in the amount of ATP available for release from platelets after exposure to thrombin. Thromboasthenic platelets are detected by elimination of the secondary phase of collagen and arachidonic acid induced ATP release. All determinations were accompanied by a simultaneously run normal blood sample and automated platelet count.

Determination of Factor VIII, von Willebrand Ag and ristocetin cofactor activity

The percentage of Factor VIII present in a test plasma was determined by the degree of correction obtained when the plasma is added to immunoabsorbed Factor VIII deficient human plasma (Dade, Baxter Healthcare Corporation Miami, FL). The degree of correction is determined by the activated partial thromboplastin time using a fibrometer (ACL3000, Izasa, Madrid, Spain). The quantitative determination of von Willebrand
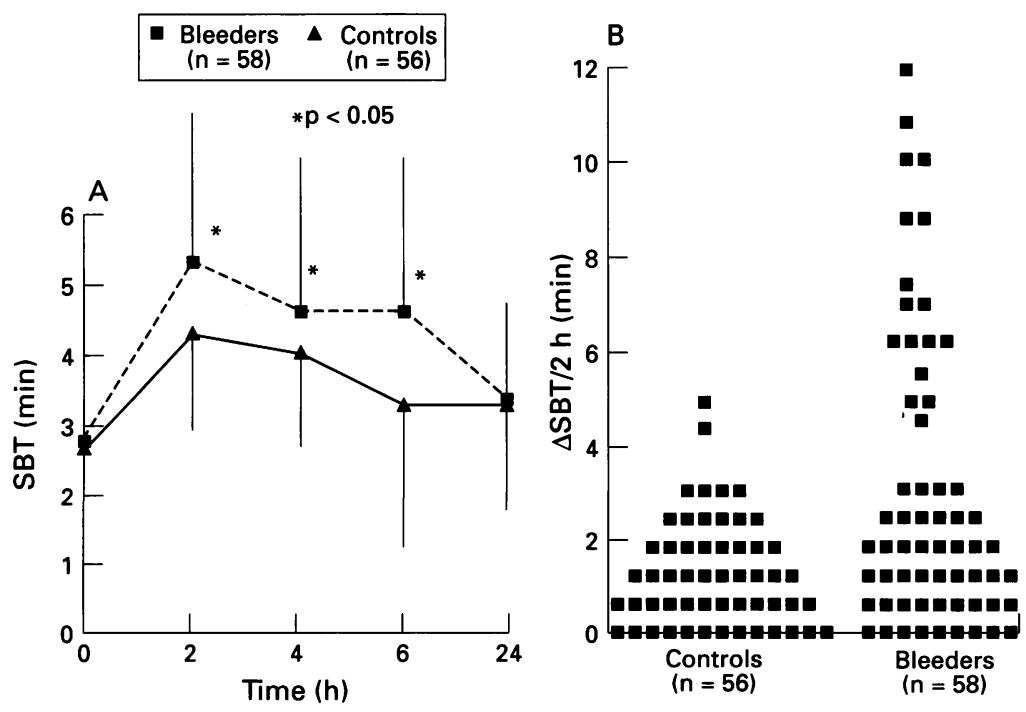

Figure 1: (A) Skin bleeding time (SBT) (mean) in bleeders and controls before and after the ingestion of $375 \mathrm{mg}$ of aspirin. (B) Individual data of $(\Delta)$ skin bleeding time two hours after aspirin use in bleeders and controls. Those values over 4.5 minutes represents patients with $(\Delta)$ skin bleeding time beyond the mean (2 SD) of controls. factor was performed by a commercial enzyme immunoassay kit (Asserachrom vWF, Boehringer Mannheim, Germany). Factor VIII ristocetin cofactor activity in plasma was determined by the ability of the test plasma and ristocetin to induce aggregation in a standardised platelet suspension and the activity interpolated from a standard curve prepared with known amounts of ristocetin cofactor activity (Biopool, Umea, Sweden).

\section{Statistical analysis}

Results are expressed as mean (SD). The Student $t$ test for equal or unequal variances were used for comparison between groups. Categorical data were analysed by means of Pearson's minimum square method or Fisher's exact test when appropriate. The MannWhitney $U$ test was used to analyse categorically ordered numerical variables. Multiple regression (general lineal models; SPSS/PC+) was used when variables were to be associated with gastrointestinal bleeding in a multivariate context. In this case, the logistic regression model was adjusted for age and sex.

\section{Results}

Characteristics of patients and controls

We studied 61 patients with a history of recent gastrointestinal bleeding associated with aspirin use and 61 age and sex matched controls (Table I). Eight (6.5\%) patients (three cases and five controls) were finally excluded from the analysis because it was found that they had used aspirin within five days of testing. Of the remaining patients, five had bled from the lower gastrointestinal tract and 53 from the upper gastrointestinal tract including 45 from peptic ulcers ( 25 duodenal ulcers, four pyloric ulcers, and 16 gastric ulcers), and eight from acute mucosal lesions. Nineteen $(76 \%)$ of the 25 duodenal ulcer patients and $12(60 \%)$ of the 20 gastric and pyloric ulcer patients were positive for Helicobacter pylori infection, which was diagnosed by urease test (CLO-Test, Delta West Ltd, Bentley, Australia) or histological examination of antral biopsy specimens, or both. Table I shows the Forrest classification of these bleeding ulcers. Fifteen cases $(25 \cdot 8 \%)$ had bled one or more times before the present episode. According to history, 30 (51.7\%) patients had longterm use of aspirin before the bleeding episode and in the other $28(48 \cdot 2 \%)$ cases that use had been sporadic. Aspirin was used in $28(48.2 \%)$ cases without prescription and in 30 cases with prescription (17 cases because of cardiovascular diseases and 13 because of rheumatic disorders).

\section{Skin bleeding time after aspirin use}

Basal skin bleeding time was similar in both bleeders and controls. Skin bleeding time increased significantly in both populations at two, four, six, and 24 hours after aspirin use, but the increase, as a group, was significantly 

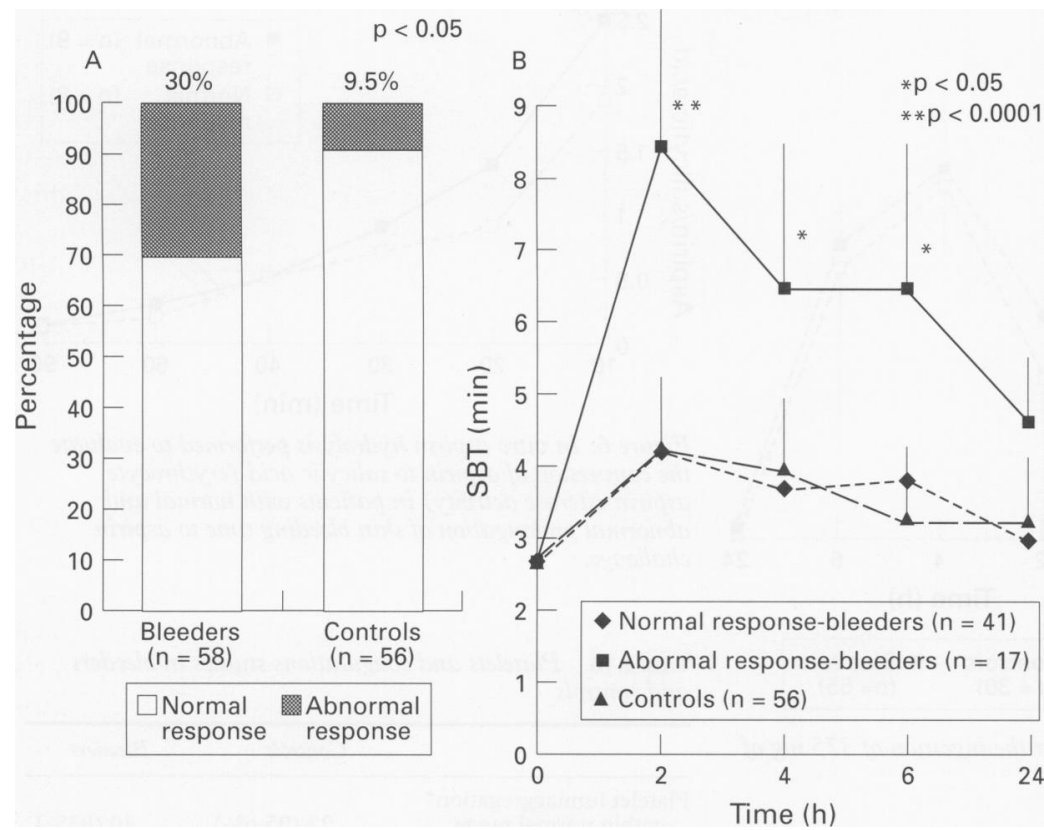

Figure 2: (A) Percentages of bleeders and controls with abnormal skin bleeding time, defined as those with a ( $\Delta$ ) skin bleeding time beyond the mean (2 SD) of controls, to aspirin challenge. (B) Skin bleeding time means in bleeders with abnormal prolongation of skin bleeding time to aspirin challenge and normal response.

higher in bleeders with the peak being at two hours and remaining high until six hours (Fig 1). As previously described ${ }^{6}$ the skin bleeding time response to aspirin was not homogeneous and some patients had a higher prolongation of the skin bleeding time than others. If we consider as abnormal an increase of the skin bleeding time greater than the mean plus $2 \mathrm{SD}$ of control values $(\Delta>4.5 \mathrm{~min})$, most 'hyperresponders' were bleeders and represented $30 \%$ of the bleeding population $v 9.5 \%$ of controls $(p<0.05)$ (Fig 2). To ensure that the skin bleeding time hyper-response to aspirin was reproducible, a second test was performed in nine of these patients and similar results were seen between the first and the second test $(\Delta$ skin bleeding time $=6.44(0.8)$ min $v 6.66$ $(0.78) \mathrm{min} ; r=0.9171)$. The calculated relative risk estimate for the occurrence of gastrointestinal bleeding in those patients who show abnormally prolonged skin bleeding time after aspirin use is $5 \cdot 4(95 \% \mathrm{CI} 1 \cdot 8$ to $17 \cdot 1)$.

TABLE II Clinical data in bleeders with and without abnormal prolongation of skin bleeding time to aspirin challenge

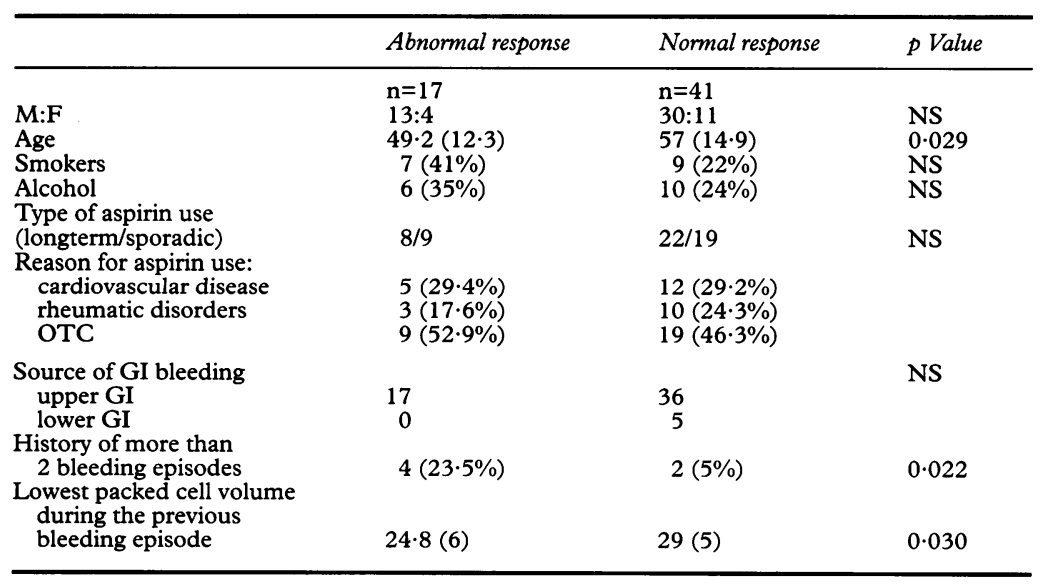

Data shown as mean (SD) and number (\%). Abbreviations as Table I.
When compared with those patients with normal skin bleeding time response, patients with abnormally prolonged skin bleeding time were similar in terms of sex, alcohol or smoking history, type and reasons of aspirin use, and source of bleeding but had a lower packed cell volume during the bleeding episode and a more frequent previous history of gastrointestinal bleeding. They also were younger than those with normal response (Table II). Patients with gastrointestinal bleeding associated with either a history of longterm or sporadic aspirin use had similar skin bleeding time after aspirin use, but those with abnormally prolonged skin bleeding time and sporadic aspirin use had the highest skin bleeding time values (Fig 3 ).

\section{Aspirin and salicylic acid values in plasma}

No differences in either aspirin or salicylic acid concentrations in plasma were found between bleeders and controls (Fig 4) or between men and women. Patients with abnormally prolonged skin bleeding time and patients older than 60 had higher concentrations of aspirin at two hours, suggesting a slower aspirin metabolism, but the differences were not statistically significant (Fig 5). In vitro aspirin hydrolysis was performed in 17 bleeders (nine of them with hyper-response to aspirin) to evaluate the erythrocyte esterase activity. As expected, salicylic acid, the main metabolite that is formed by aspirin hydrolysis, increased with time but no differences could be seen in those with higher skin bleeding time response to aspirin (Fig 6).

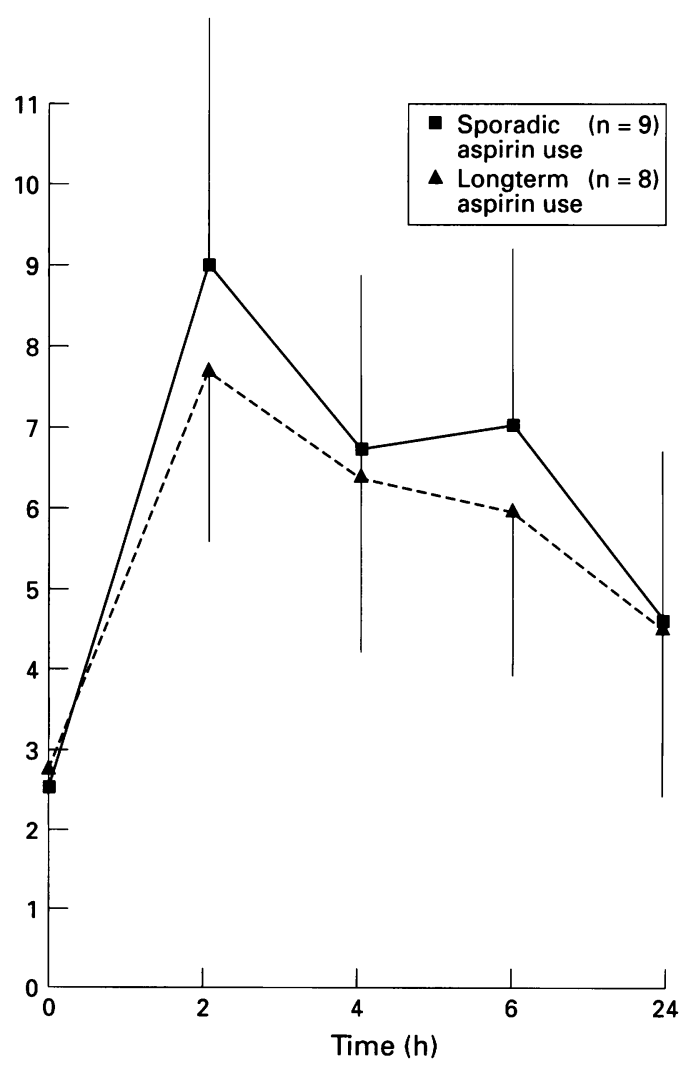

Figure 3: Skin bleeding times (mean) in bleeders with hyper-response to aspirin and a history of either longterm or sporadic use. 

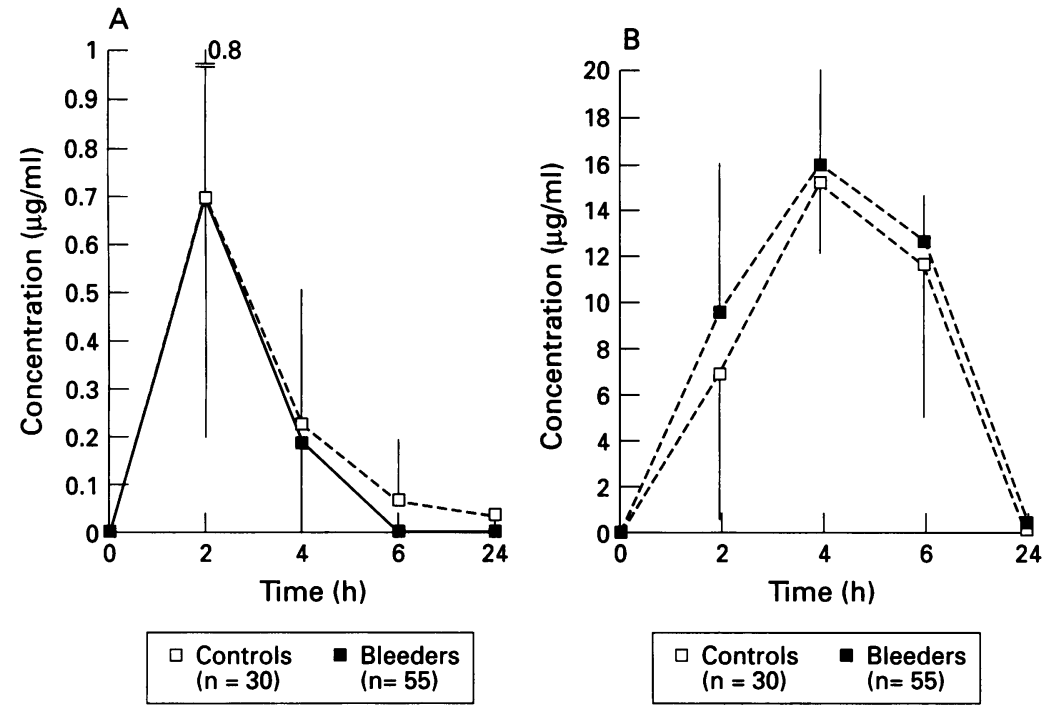

Figure 4: Aspirin (A) and salicylic acid (B) concentrations after the ingestion of $375 \mathrm{mg}$ of aspirin in bleeders and controls.
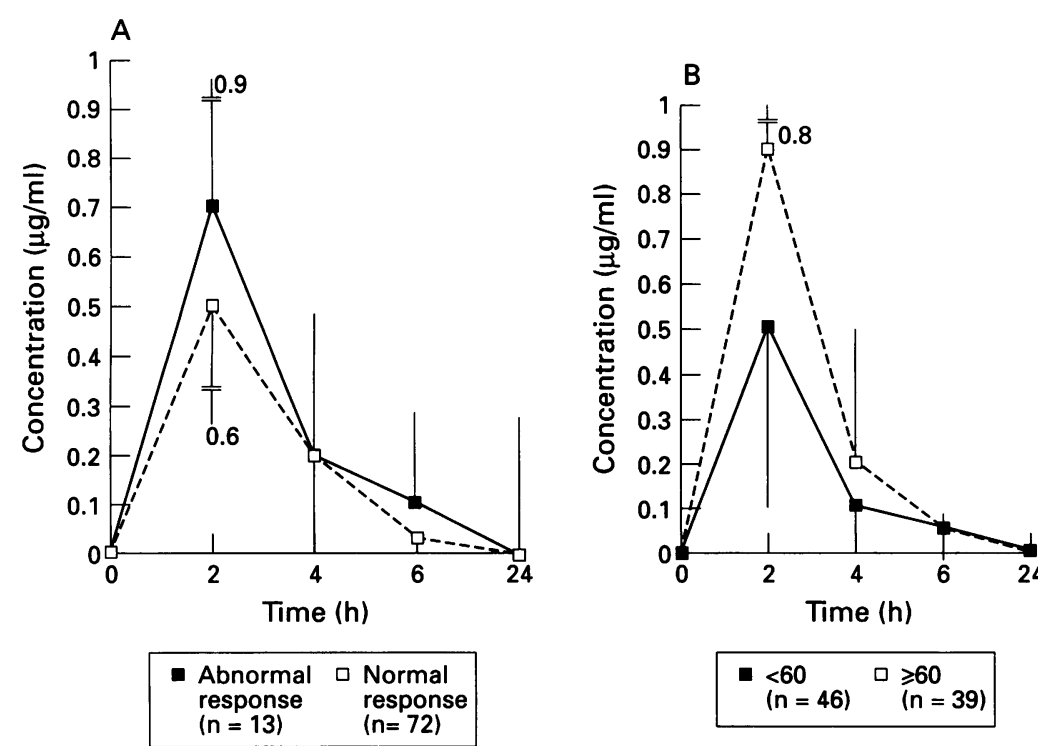

Figure 5: (A) Aspirin concentrations after the ingestion of $375 \mathrm{mg}$ of aspirin in patients with or without abnormal prolongation of skin bleeding time to aspirin challenge. (B) Aspirin concentrations after the ingestion of $375 \mathrm{mg}$ of aspirin in patients under and over 60 years of age.

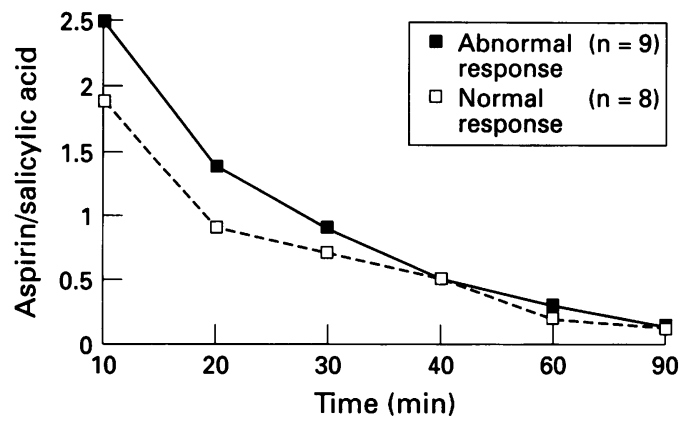

Figure 6: In vitro aspirin hydrolysis performed to evaluate the conversion of aspirin to salicylic acid (erythrocyte aspirin esterase activity) in patients with normal and abnormal prolongation of skin bleeding time to aspirin challenge.

TABLE III Platelets and coagulations studies in bleeders and controls

\begin{tabular}{lcc}
\hline & Controls & Bleeders \\
\hline $\begin{array}{l}\text { Platelet lumiaggregation } \\
\text { within normal range }\end{array}$ & $22(95 \cdot 6 \%)$ & $40(93 \%)$ \\
decreased (non-specific) & $1(4 \cdot 3 \%)$ & $3(6 \cdot 9 \%)$ \\
F VIII-c & $105 \cdot 3(9 \cdot 5)$ & $105(14)$ \\
F VIII-Ag & $100(13)$ & $100 \cdot 6(8)$ \\
F VIII-cR & $99 \cdot 7(3 \cdot 5)$ & $99 \cdot 8(5)$ \\
Pro Act & $97 \cdot 2(14 \cdot 8)$ & $100 \cdot 1(13)$ \\
APTT & $31.5(2 \cdot 4)$ & $30 \cdot 7(3.5)$ \\
\hline
\end{tabular}

F VIII c=Factor VIII-normal range (70-120\%). F VIII $\mathrm{Ag}=$ Factor Von Willebrand antigen-normal range $(60-150 \%)$. F VIIICR=Factor VIII ristocetin cofactor activity-normal range $(>40 \%)$. Pro Act=prothrombin activity-normal range $>80 \%$. $>40 \%$ ). Pro Act $=$ prothrombin activity-normal range $>80 \%$
APTT $=$ Activated partial thromboplastin time-normal range APTT $=$ Activated partial thromboplastin time-normal range
$32-46$ seconds. $\star$ Platelet lumiaggregation studies were $32-46$ seconds. ${ }^{\star}$ Platelet lumiaggregation studies were
performed in 66 people (including all patients with prolonged skin bleeding time). Data shown as number (\%) and mean (SD).

TABLE IV Logistic regression analysis ${ }^{\star}$ to evaluate independent variables affecting gastrointestinal bleeding associated to aspirin use

\begin{tabular}{lll}
\hline Variable & Coefficient & Significance \\
\hline Alcohol & - & 0.4834 \\
Smoking & -3.0971 & 0.0165 \\
Platelets & - & 0.8590 \\
Platelet lumiaggregation & - & 0.1440 \\
$\quad \begin{array}{l}\text { studies } \\
\text { Skin bleeding time }\end{array}$ & -2.4470 & 0.0165 \\
$\quad \begin{array}{l}\text { after aspirin } \\
\text { Constant }\end{array}$ & 4.3522 & 0.0113
\end{tabular}

^Age and sex included in the model.

Platelets and coagulation test studies

Platelet lumiaggregation studies were within normal ranges in most bleeders and controls and only minor and non-specific abnormalities could be detected in a few patients. Potential subclinical von Willebrand disease and any other defects were also ruled out (Table III).

Multivariate analysis

To identify independent risk factors related to gastrointestinal bleeding, a multiple regression analysis was performed with all variables of the study. When the presence of a history of gastrointestinal bleeding was chosen as the dependent variable, the independent variables affecting aspirin related gastrointestinal bleeding in the equation were the presence of a prolonged skin bleeding time response to aspirin and smoking (Table IV).

\section{Discussion}

It is well established that gastrointestinal bleeding is associated with NSAID use, ${ }^{23}$ and current data suggest that over $80 \%$ of both upper and lower gastrointestinal bleeders have used NSAID, most of them aspirin, within five days. ${ }^{1}$ An increased risk of complications seems to be related to drug dose, but even low doses of aspirin, as those used in cardiovascular prophylaxis, increase the risk. ${ }^{214-19}$ In fact, most bleeders use less than $600 \mathrm{mg}$ per day of aspirin, ${ }^{5}$ and in our population a third of those patients with a history of aspirin related gastrointestinal bleeding were taking $\leqslant 200 \mathrm{mg}$ of aspirin per day for cardiovascular prophylaxis. Thus, bleeding often seems to be a direct consequence of NSAIDs and especially aspirin use. However, it is also apparent that most of those using NSAIDs are free from complications. $^{2} 1620$ 
The mechanisms whereby aspirin might promote or induce bleeding in only a small proportion of users are not known. Therefore, it would be helpful to establish possible mechanisms or markers to account for the unpredictable cases of gastrointestinal bleeding as a consequence of aspirin use. One such mechanism could be related to platelet dependent clotting mechanisms, which are inhibited by NSAIDs, especially aspirin. Aspirin affects platelet aggregation in all, but increases skin bleeding time only in some normal subjects. ${ }^{21-25}$ In this study, basal skin bleeding time was not different between patients and controls, and aspirin also increased skin bleeding time in both groups, but we found that the skin bleeding time increase was significantly higher in patients with a history of aspirin related gastrointestinal bleeding than in controls. Furthermore, in almost a third of bleeders the increase was outside (2SD) the range found in non-bleeder controls. These results may explain recent data reported by Day et $a l^{5}$ who found an abnormal prolongation of skin bleeding time in acute gastrointestinal bleeders that used aspirin, when tested soon after hospital admission. ${ }^{5}$

As previously reported, ${ }^{6}{ }^{24}{ }^{26-28}$ we were able to show two populations with respect to skin bleeding time prolongation after aspirin use. A subset of people, termed 'hyper-responders', had a skin bleeding time increase greater than $2 \mathrm{SD}$ beyond the mean prolongation found in controls that had never bled. There were significantly more hyper-responders among bleeders than among controls, suggesting that a wide subset of patients with aspirin related gastrointestinal bleeding may have a special susceptibility for digestive bleeding when exposed to aspirin. In fact, prolonged skin bleeding time after aspirin use was an independent variable that could be related to a history of aspirin related gastrointestinal bleeding. When compared with those with normal response, the $30 \%$ of patients with abnormally prolonged skin bleeding time had a different pattern of gastrointestinal bleeding showing not only a history of more episodes of bleeding but also more severe bleeding. However, a prolonged skin bleeding time does not necessarily indicate more prolonged gastric bleeding. Although Daneshmend et $a l^{29}$ found that gastric bleeding, induced by gastric mucosal biopsy endoscopic forceps followed by lavage, was higher after high dose aspirin intake than after placebo, O'Laughlin et $a l^{30}$ reported that 'gastric bleeding time' was unaffected by one or 14 days of aspirin use. Also in another study, ${ }^{31}$ upper gastrointestinal bleeders (six of whom had used aspirin) had a shorter gastric bleeding time than controls, suggesting an increased gastric haemostasis in bleeders. Nevertheless, clinical gastric bleeding arises from deeper vessels than are reached by biopsy forceps and these findings made in a comparatively low number of patients may not be relevant. Therefore, it is possible that in the 'susceptible' population we have found, aspirin is an important trigger for bleeding from pre-existing or drug induced mucosal lesions, while other people without this potential susceptibility may have only a subclinical or non-significant bleeding when exposed to aspirin.

The existence of underlying potential intrinsic platelet defects or the presence of subclinical von Willebrand disease, which could explain the abnormal prolongation of skin bleeding time and induce an abnormal gastrointestinal bleeding in susceptible patients when exposed to aspirin was an attractive hypothesis. ${ }^{28}$ However, this possibility can be ruled out after this study. In the same way, as previously shown by Fiore et $a l,{ }^{6}$ the nature of the prolonged skin bleeding time found in some of our bleeders could not be explained as a consequence of an abnormal aggregation of stimulated platelets either. Therefore, underlying platelet defects, as measured by current tests, do not account for the unpredictable cases of gastrointestinal bleeding as a consequence of aspirin use. However, the existence of defective signal transduction in platelets (for example cAMP, cGMP or $\mathrm{Ca}^{++}$) has not been evaluated but deserves further study.

Aspirin has a transient effect on skin bleeding time despite long-lasting effects on platelet cyclooxygenase activity in both bleeders and controls, ${ }^{15}$ which suggest that prolonged skin bleeding time is not solely a function of platelet inhibition. A preliminary report in animals suggested that the arrest of gastric haemorrhage was independent of platelet aggregation and was primarily brought about by processes involving the coagulation system, ${ }^{32}$ but a recent study in humans showed that aspirin induced gastric mucosal bleeding was not increased by heparin pretreatment. ${ }^{21}$ An abnormal prolongation of skin bleeding time in uraemia patients was reported to be associated with the presence of aspirin in circulating blood, ${ }^{22}$ which could interact with other platelet functions. In this study, aspirin and salicylic acid values in plasma were similar in both bleeders and controls, and aspirin concentrations after six hours were indetectable while skin bleeding time was still more prolonged in bleeders, suggesting that the presence of aspirin in circulating blood is not associated with prolonged skin bleeding time in bleeders and also that the aspirin metabolism is not different in bleeders and controls. Aspirin metabolism and blood red cell dependent aspirin hydrolysis were slower but not statistically different in those patients with a greater skin bleeding time response to aspirin. It is possible that more specific studies on aspirin pharmacokinetics and bioavilability could detect differences in a subset of gastrointestinal bleeders, but the meaning and significance of this will await further studies.

Age is considered a risk factor for gastrointestinal bleeding among those patients who use NSAIDs. ${ }^{33}$ Our results show that those patients with abnormal skin bleeding time response after aspirin use were younger than those with normal response. It is possible that this difference could be a consequence of the different skin composition in younger versus 
older people (for example, elasticity, water content, etc), but it may indicate the existence of different pathophysiological basis for bleeding in these populations. Further research is needed to confirm and explain the potential importance of this finding.

In summary, when rechallenged with aspirin after recovery, aspirin related upper gastrointestinal bleeders, as a group, had a higher skin bleeding time response to aspirin when compared with controls. A third of this population showed an increase beyond the normal range for controls. These patients also had a history of more severe bleeding and more episodes of previous bleeding but this was not related to any known subclinical condition or platelet defect. It is not clear whether prolonged skin bleeding time in aspirin users is the expression of abnormal bleeding mechanisms in a subset of susceptible patients or just a marker of bleeding risk in aspirin users. Furthermore, this study shows that there are no markers or mechanisms yet shown in $70 \%$ of aspirin related bleeders. These questions await further research.

This study was supported by research grant from the Asociación de Investigaciones Gastroenterológicas de la Provincia de Zaragoza.

Zaragoza.
The authors thank the Service of Epidemiology of the

The authors thank the Service of Epidemiology of the
University Hospital for assistance with statistical analysis and Pilar Vadillo for her inestimable technical assistance.

1 Lanas A, Sekar MC, Hirschowitz BI. Objective evidence of aspirin use in both ulcer and non-ulcer upper and lower aspirin use in both ulcer and non-ulcer upper and lower gastrointe

2 Langman MJS, Weil J, Wainwright $P$, Lawson DH, Rawlins XX, Logan RFA, et al. Risks of bleeding peptic ulcer associated with individual non-steroidal antiinflammatory drugs. Lancet 1994; 343: 1075-8.

3 Faulkner G, Prichard P, Somerville K, Langman MJ. Aspirin and bleeding peptic ulcers in the elderly. $B M \mathcal{F}$ 1988; 297: 1311-3.

$4 \mathrm{McCarthy}$ DM. Nonsteroidal anti-inflammatory drugs - the clinical dilemmas. Scand $\mathcal{F}$ Gastroenterol 1992; 27 (suppl 192): 9-16.

5 Day JP, Lanas A, Rustagui P, Hirschowitz BI. Reversible prolonged skin bleeding time due to aspirin, found in prolonged skin bleeding time due to aspirin, found in 1996; 22: 96-103.

6 Fiore LD, Brophy MT, Lopez A, Janson P, Deykin D. The bleeding time response due to aspirin. Identifying the hyperresponder. Am $\mathcal{F}$ Clin Pathol 1990; 94: 292-6.

7 Stuart MJ, Miller ML, Davey FR, Wolk JA. The post aspirin bleeding time: a screening test for evaluating hemostatic disorders. Br $\mathcal{F}$ Haematol 1979; 43: 649-59.

8 Smith C. Surgicutt: A device for modified template bleeding times. $\mathcal{F M}$ Med Tech 1986; 3: 229-31.

9 Mielke Ch, Kaneskiro MM, Maher Y, Weiner JM, Rapaport SI. The standardized normal Ivy bleeding time and its prolongation by aspirin. Blood 1969; 34: 204-15.
10 Deykin D, Janson P, McMaron L. Ethanol potentiation of aspirin-induced prolongation of the bleeding time. $N$ Engl fMed 1982; 8: 852-4.

11 Bakar SK, Niazi S. High-performance liquid chromatographic determination of aspirin and its metabolites in tographic determination of aspirin and its metabolit

12 Connor AM, Laposata M. A rapid assay for platelet thromboxane production and its use assessing prior thromboxane production and its use assessing

13 Mieuwenhuis K, Akkerman JWN, Sixma JJ. Patients with a prolonged bleeding time and normal aggregation test may have storage pool deficiency: studies on one hundred and six patients. Blood 1987; 78: 620-3.

14 Henry D, Dobson A, Turner C. Variability in the risk of major gastrointestinal complications from nonaspirin nonsteroidal anti-inflammatory drugs. Gastroenterology 1993; 105: 107-8.

15 Willard JE, Lange RA, Hillis DL. The use of aspirin in ischemic heart disease. $N$ Engl f Med 1992; 327: 175-81.

16 Kurata JH, Abbey DE. The effect of chronic aspirin use on duodenal and gastric ulcer hospitalizations. I Clin duodenal and gastric ulcer

17 Nyman I, Larsson H, Wallentin L. Prevention of serious cardiac events by low-dose aspirin in patients with silent myocardial ischaemia. Lancet 1992; 340: 497-501.

18 The Dutch TIA Study Group. A comparison of two doses of aspirin ( $30 \mathrm{mg}$ vs. $283 \mathrm{mg}$ a day) in patients after a transient ischemic attack or minor ischemics stroke. $N$ Engl f Med 1991; 325: 12261-6.

19 Silagy CA, McNeil JJ, Donnan GA, Tonkin AM, Worsan B, Campion K. Adverse effects of low-dose aspirin in a healthy elderly population. Clin Pharmacol Ther 1993; 54: 84-9.

20 Langman MJS. Ulcer complications and nonsteroidal antiinflammatory drugs. Am $₹$ Med 1988; 84: 15-9.

21 Bang CJ, Riedel B, Talstad Y, Berstad A. Interaction between heparin and acetylsalicylic acid on gastric between heparin and acetylsalicylic acid on gastric Gastroenterol 1992; 27: 489-94.

22 Gaspari F, Vigano G, Orisio S, Bonati $M$, Livio $M$, Remuzzi G. Aspirin prolongs bleeding time in uremia by a mechanism distinct from platelet cyclooxygenanase inhibition. $\mathcal{f}$ Clin Invest 1987; 79: 1788-97.

23 Hirsch J, Street D, Cade JF, Amy H. Relation between bleeding time and platelet connective tissue reaction after aspirin. Blood 1973; 41: 369-77.

24 Stuart MJ, Miller ML, Davey FR, Wolk JA. The post aspirin bleeding time: a screening test for evaluating hemostatic disorders. $\mathrm{Br} \mathcal{f}$ Haematol 1979; 43: 649-59.

25 Buchanan GR Holkamp CA. A comparative study of variables affecting the bleeding time using two disposable variables affecting the bleeding time using

26 Barber A, Green D, Galluzo T, Tsao CH. The bleeding time as a preoperative screening test. $\mathrm{Am} \mathcal{F} \mathrm{Med}$ 1985; 78: 761-4.

27 Bick R, Adams T, Schmalhorst W. Bleeding times, platelet adhesion and aspirin. Am $\mathcal{F}$ Clin Pathol 1976; 65: 69-72.

28 Kumar R, Ansell SE, Canoso RT, Deykin D. Clinical trial of new bleeding time device. Am $\mathcal{F}$ Clin Pathol 1978; 70: 642-5.

29 Daneshmend TK, Sharma HK, Hawthorne AB, Bhaakar NK, Hawkey CJ. A new measure, the gastric bleeding time prolongation by aspirin in human. Gastroenterology 1989; 96: 108A.

30 O'Laughlin J, Hoftiezer J, Mahoney J, Ivey K. Does aspirin prolong bleeding from gastric biopsies in man? prolong bleeding from gastric

31 Allison MC Fularton GM, Brown IL Crean GP, McColl KEL. Enhanced gastric mucosal haemostasis after upper gastrointestinal haemorrhage. Gut 1991; 32: 735-9.

32 Whittle BJR, Kauffman GL Jr, Moncada S. Hemostatic mechanisms independent of platelet aggregation arrest gastric mucosal bleeding. Proc Natl Acad Sci USA 1986; 83: $5683-7$.

33 Sherine E, Gabriel MD, Kkmainer LJ, Bombadier C. Risk for serious gastrointestinal complicationss related to use of nonsteroidal antiinflammatory drugs. Ann Intern Med 1991; 115: 787-96. 